\title{
USING INSAR STACKING TECHNIQUES TO PREDICT BRIDGE COLLAPSE DUE TO SCOUR
}

\author{
Sivasakthy Selvakumaran ${ }^{1}$, Simon Plank ${ }^{2}$, Cristian Rossi ${ }^{3}$ and Christian Gei $\beta^{2}$ \\ (1) University of Cambridge Engineering Department, UK \\ (2) German Aerospace Center (DLR), Germany \\ (3) Satellite Applications Catapult, UK
}

\begin{abstract}
Failure of bridges due to scour is of great concern to bridge asset owners, and is currently very difficult to predict and monitor regularly using conventional assessment methods. This paper presents evidence of how InSAR techniques can be used to monitor bridges at risk of scour, using Tadcaster Bridge, England, as a case study. Tadcaster Bridge suffered a partial collapse due to river scour on the evening of December 29th, 2015 following a period of severe rainfall and flooding. SAR scenes over the bridge from the two-year period prior to the collapse are analysed using SBAS interferometry methods, highlighting a distinct movement in the region of the bridge where the collapse occurred prior to the actual event. This precursor to failure observed in the data suggests the possible use of InSAR in structural health monitoring of bridges at risk of scour, as a means of an early warning system.
\end{abstract}

Index Terms - Interferometric synthetic aperture radar (InSAR), TerraSAR-X, bridge, structural health monitoring (SHM), scour

\section{INTRODUCTION}

The deterioration and collapses of bridges, dams, tunnels and other key services highlights the essential importance of inspection and structural health monitoring (SHM) as a tool to aid infrastructure asset owners and managers. Space-borne synthetic aperture radar (SAR) interferometry (InSAR) provides a means to assess millimetre-scale deformation over large geographical areas from satellites orbiting the earth [1]. Developments over the last decade mean that modern X-band SAR-sensors are able to collect imagery with spatial resolution of a metre, or even sub-metre, scale depending on the acquisition mode. Such spatial scales can enable the coverage of single infrastructure assets with a number of pixels and provide information about asset behaviour [2][3]. With

TerraSAR-X data has been provided by the German Aerospace Centre (DLR). Thanks also go to John Smith and North Yorkshire County Council for their support. This work was made possible by EPSRC (UK) Award 1636878, with iCase sponsorship from the National Physical Laboratory. rapidly changing environmental conditions accelerated by climate change (including temperature variations and increased flooding) monitoring key structures such as bridges becomes vital both for maintaining the flow of local economies, as well as protecting the safety of citizens.

Current infrastructure asset maintenance practices in most countries centre on periodically scheduled visual inspections to assess asset condition, performance and levels of deterioration in order to prevent potential failures and other potentially serious consequences. Visual inspections are reliant upon a subjective human element to assess risks and deterioration. On the one hand, this is invaluable in providing a tailored approach, but on the other hand it introduces a question of reliability [4]. Installing SHM sensor systems does not always yield value and is not a financially viable or practical option for all assets [5].

In the case of bridges over water bodies (with piers or abutments under the water surface) it is especially difficult to inspect foundations to assess whether any erosion or damage has occurred. Traditionally, inspections are undertaken by sending divers to assess damage - a process that is risky for divers and often cannot be undertaken during flood events when bridges are especially vulnerable. Scour is the primary cause of bridge failure in the United States [6] and is identified as one of the top concerns by the UK Bridge Owners' Forum.

Remote sensing from satellites provides means of complementing such visual inspections with more objective data, collected over wide areas, and in significantly more frequent intervals than visual inspections. It can provide supplementary data which would not traditionally be captured by visual inspection, such as small-scale deformations, or deformations of the ground in the surrounding region. It can also provide a method to monitor assets that are difficult to access or are otherwise unable to be inspected as frequently as desired. Previous work on bridge monitoring in particular has highlighted the potential of InSAR to be used as part of early warning systems to identify precursors to failure [7]. This study presents work on a new case study, in which localised deformation is observed in a short period of time prior to collapse. 


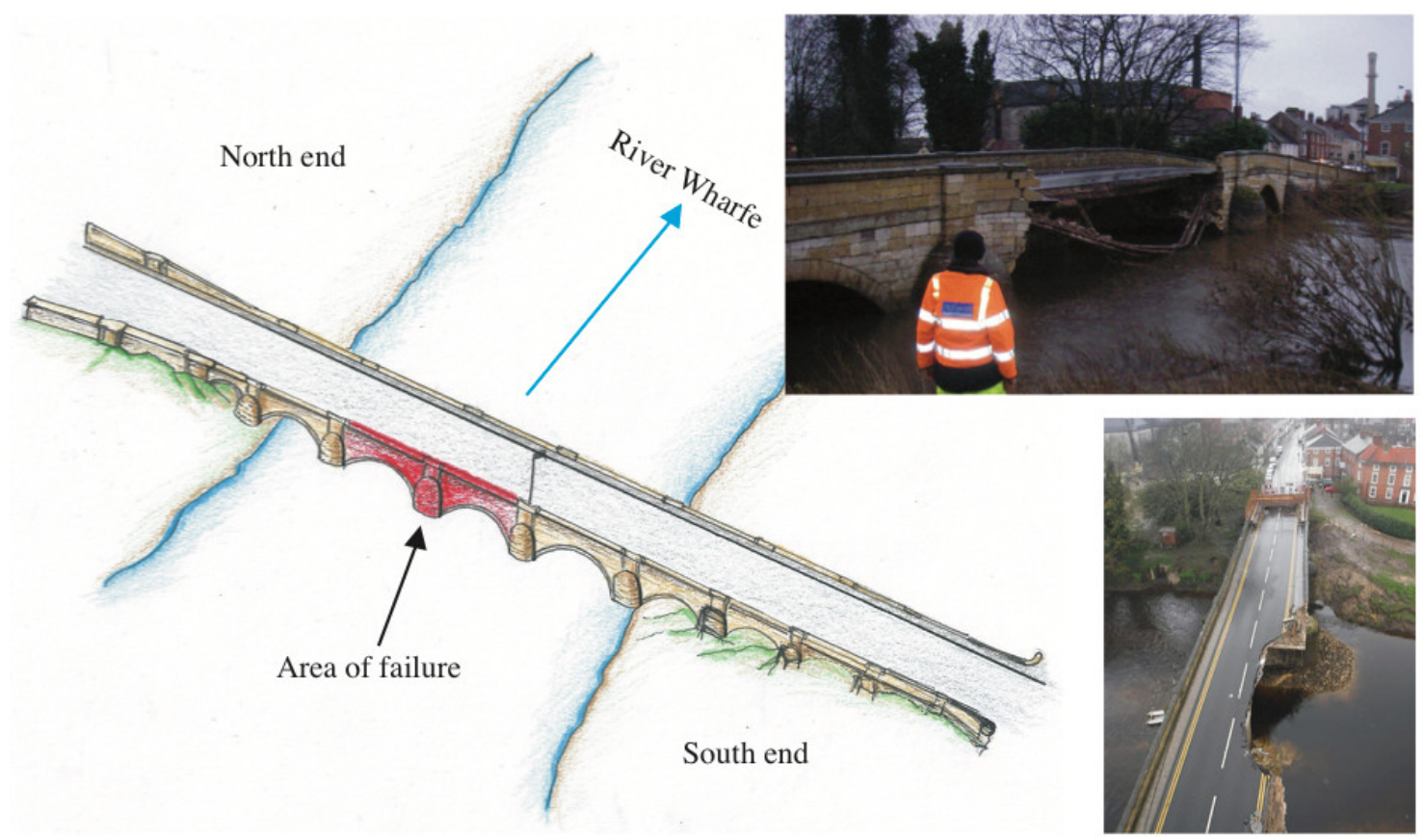

Fig. 1. Schematic of Tadacaster Bridge highlighting area of failure in red and photos showing extent of failure. Tadcaster Bridge after partial collapse. The collapse occurred in a central span over the river, on the north side of the bridge; the rest of the bridge remained in tact.

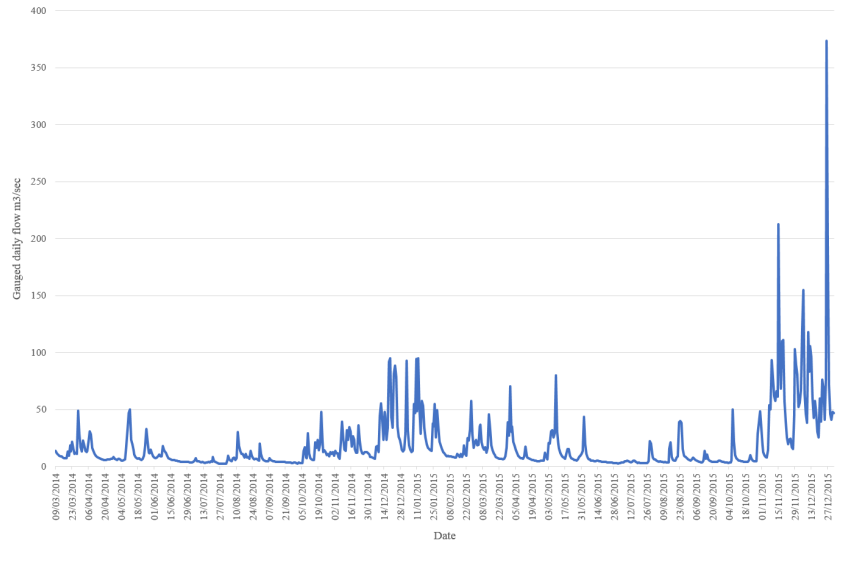

Fig. 2. Gauged river flow from station 27089 Wharfe at Tascaster for period covered by this study. Data from the UK National River Flow Archive.

\section{MONITORING SCOUR FAILURE}

Scour is a natural phenomenon caused by the excavation and removal of material from the bed and banks of streams as a result of the erosive action of flowing water. When this removal of sediment occurs to material surrounding or supporting piers and foundations of a bridge, there is an increased risk of undermining the bridge and causing collapse of the pier. Scour increases with increasing flow rates, making structural collapse of structures more likely during periods of extreme flow, such as flooding.

Standard practice for monitoring and measuring scour is to conduct initial scour assessments to identify those structures at risk of scour, for which a minimum inspection interval may be set. Inspections are currently undertaken using diver inspections at set time intervals (typically annually) and after major flood events. There are limitations to when this procedure can occur, and even when diver is sent, they may not realise there's a problem (for example, when loose material backfill hides the problem).

\section{CASE STUDY}

On December 29th 2015, following a period of substantial flooding, the A659 road bridge at Tadcaster suffered a partial collapse on the upstream face (Figure 1). Tadcaster Bridge is a historic nine-arch masonry bridge over the River Wharfe in Tadcaster. It is approximately $100 \mathrm{~m}$ long and $10 \mathrm{~m}$ wide, carrying a single lane of vehicular traffic in each direction and a pedestrian walkway on each side.

The present bridge (prior to collapse) comprises two structures of different dates, built side by side to expand the width of the original structure. Documentary evidence [8] suggests it "was built in 1698-9 replacing an earlier bridge on the same site that had been recently swept away by flood. The deck of the 1698 bridge was then raised and its west end widened slightly (probably in 1736 and 1753 respectively), 


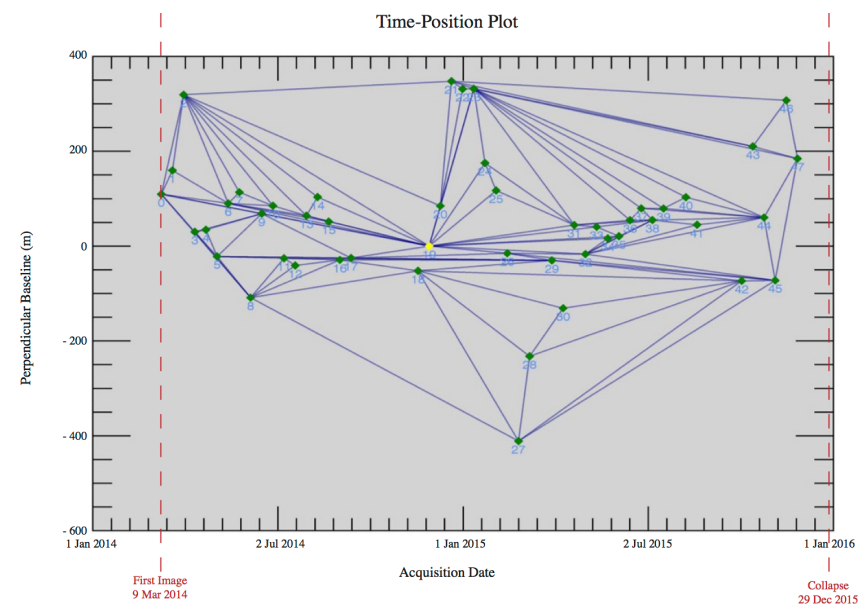

Fig. 3. Temporal vs perpendicular baseline distributions for the interferometric stack of SAR images used in this study; the small baseline interferograms computed are represented by the connections between points. Three dimensional unwrapping was used to exploit the temporal information to help unwrapping the low coherent interferogram areas, looking at the other coherent pairs.

before a second bridge was built alongside it upstream in 1791-2, effectively doubling the width of the river crossing".

The final stages of the failure of Tadcaster Bridge were captured on video as it collapsed, where a pronounced dip in the masonry is seen prior to the pier below giving way. The River Wharfe had been swollen in the months preceding the collapse, with heavy rainfall starting in late October, continuing through November and December. River gauging stations at Tadcaster and a site upstream recorded their highest ever river flow since in 25 years of records of $547 \mathrm{~m} 3 / \mathrm{s}$ and data from UK National River Flow Archive (Figure 2) shows larger river volumes in the winter of 2015, prior to collapse. The severe conditions of persistent high flow would have accelerated scour behaviour; though such small deformations are not visible to eye, the initial signs of this movement is picked up in the SAR data.

\section{DATA}

The analysis of movements of this bridge was carried out using 48 Stripmap SAR images from the TerraSAR-X satellite, covering a period from 9th March 2014 until 26th November 2015, the final acquisition being the last available image prior to the bridge collapse. Unfortunately, no SAR scenes were available between the end of November and the collapse on December 29th. The stack of acquisitions in Stripmap Mode have $3 \mathrm{~m} \times 3 \mathrm{~m}$ ground resolution, taken in the ascending pass with a mean incident angle of 21.4 degrees, $\mathrm{HH}$ polarization. Shuttle Radar Topography Mission (SRTM) data with resolution of 3 arc-second (90m) was used as a Digital Elevation

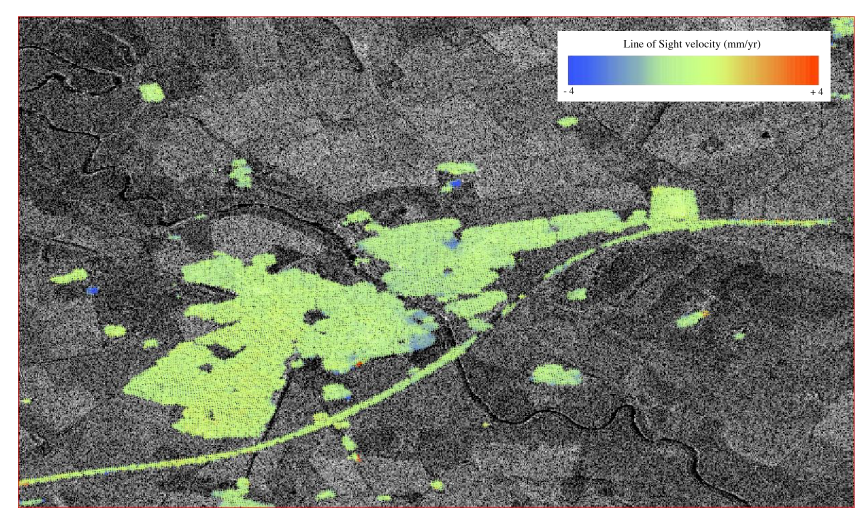

Fig. 4. Geocoded SBAS results superimposed over mean SAR amplitude image of the analysed area. The River Wharfe can be seen in the SAR image as a dark meandering line, and the Tadcaster bridges can be seen as scatterer points crossing this dark line.

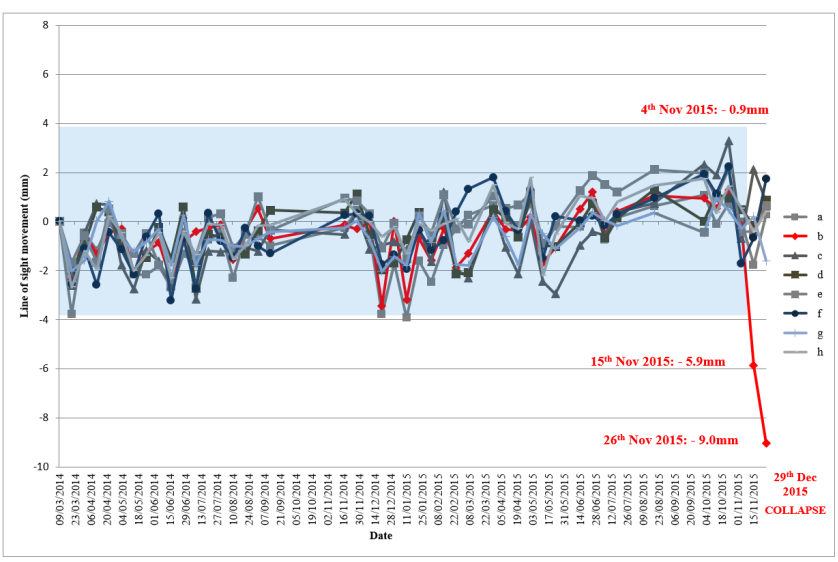

Fig. 5. Line of sight movement of scatter points identified as being from the bridge plotted over time.

Model (DEM) used during the interferometric processing.

\section{PROCESSING METHODOLOGY}

Long-term millimetre-level deformation monitoring over large areas is made possible by techniques that make use of interferometry using multiple SAR images. Persistent or Permanent Scatterer Interferometry (PSI) uses reflectors whose response to the radar is dominated by a strong reflecting object and is constant over time. It does not impose any constraint on the temporal and spatial baselines of the exploited multi-temporal differential interferograms. A procedure for the identification and exploitation of stable permanent scatterers was developed by Ferretti et al. [9]. The technique relies on analysing pixels which remain fixed, or coherent over a sequence of interferograms.

Small Baseline Subset (SBAS) techniques, in contrast to 
PSI techniques, impose constraints on the maximum temporal and spatial baselines, but also allow the analysis of distributed targets [10]. The basis of the SBAS technique uses pairs of low-pass filtered (multilook) DInSAR interferograms. The data pairs involved in the generation of the interferograms are properly selected in order to minimize the spatial, temporal and Doppler separation (baseline) between the acquisition orbits, thus limiting the decorrelation phenomena. Figure 3 illustrates the pairs of images formed.

\section{RESULTS AND DISCUSSION}

Figure 4 shows the mean SAR amplitude image of the analysed area, with the geocoded scatterers (selected using SBAS methods) superimposed to visually understand where these scatterer points might be reflecting from. A key difficulty in applying InSAR techniques to structural monitoring is the physical interpretation of the reported coherent scatterers.

The InSAR process relies on the reflected backscatter of SAR emitted from satellites. This generally works best in urban areas with hard, sharp surfaces (shown in Figure 4 by scatterers present in areas of buildings and built infrastructure). Water bodies are often quite easy to identify in InSAR imagery as they correspond to low backscattered radiation (visible as darker pixels in SAR imagery) and are incoherent and not picked up by interferometry methods. In identifying the location of River Wharfe, there are two regions at which pixels clearly cross this water boundary; this can be inferred to be the A659 road bridge of interest, and another larger road bridge on the A64 motorway.

The movement over time of the points attributed to the A659 Tadcaster Bridge are plotted in Figure 5. It is worth noting that the displacement detected is in the line of sight (LOS) of the SAR satellite. Tadcaster Bridge suffered a partial collapse of one side of the structure, indicating that severe deformation should only be visible on one side of the structure in one of the central spans of the bridge. Of the points attributed to the bridge (those plotted and labelled 'a' to ' $h$ ' on Figure 5), the majority stay reasonably steady over time, though the movement of scatterer marker ' $b$ ' marked in red shows a notable deformation leading up to the collapse. The geospatial location of marker ' $b$ ' within the cluster of bridge scatterer points, matches the side and middle of river pier location where the partial collapse occurred.

Computing the standard deviations of the mean from the points attributed to the bridge reveals a value of $3.88 \mathrm{~mm}$. The two most recent deviation measurements from scatterer marker ' $b$ ' lay outside this range of 'normal' behaviour observed over the presented time period (region marked in blue in Figure 5). This suggests unusual behaviour giving rise to a precursor or warning of subsequent failure.

The techniques presented in this paper were able to identify displacements indicating the precursors to the failure due to scour of a bridge, one month prior to ultimate failure.

\section{REFERENCES}

[1] R. Bamler and P. Hartl, "Synthetic aperture radar interferometry - Topical review," Inverse Problems, vol. 14, no. 4, R1-R54, IOP Publishing Limited (UK), 1998.

[2] M. Lazecky, I. Hlavacova, M. Bakon, J. J. Sousa, D. Perissin, and G. Patricio, "Bridge Displacements Monitoring Using Space-Borne X-Band SAR Interferometry," IEEE Journal of Selected Topics in Applied Earth Observations and Remote Sensing, vol. 10, no. 1, pp. 205-210, 2017.

[3] G. Fornaro, D. Reale, and S. Verde, "Monitoring thermal dilations with millimetre sensitivity via multidimensional SAR imaging," Proc. Tyrrhenian Work. Adv. Radar Remote Sens. From Earth Obs. to Homel. Secur., Naples, Italy 2012, pp. 131-135.

[4] M. Moore, B. Phares, B. Graybeal, D. Rolander, and G. Washer, "FHWA-RD-01-020 Reliability of Visual Inspection for Highway Bridges - Volume I: Final Report," US Department of Transportation, Federal Highway Administration, Washington, 2001.

[5] G. T. Webb, P. J. Vardanega, and C. R. Middleton, "Categories of SHM Deployments: Technologies and Capabilities," ASCE Journal of Bridge Engineering, vol. 20, no. 11, p. 04014118, 2015. http://dx.doi.org/10.1061/(ASCE)BE.19435592.0000735

[6] National Academies of Sciences, Engineering, and Medicine, "Monitoring Scour Critical Bridges," The National Academies Press, Washington, DC, 2009. https://doi.org/10.17226/22979

[7] J. J. Sousa and L. Bastos, "Multi-temporal SAR interferometry reveals acceleration of bridge sinking before collapse," Nat. Hazards Earth Syst. Sci., vol. 13, no. 3, pp. 659-667, 2013.

[8] M. Jecock and L. Jessop, "Tadcaster Bridge, Tadcaster, North Yorkshire: Assessment of Significance," Historic England, Portsmouth, UK, 2016.

[9] A. Ferretti, C. Prati, and F. Rocca, "Nonlinear subsidence rate estimation using permanent scatterers in differential SAR interferometry," IEEE Transactions on Geoscience and Remote Sensing, vol. 38, no. 5, pp. 2202-2212, 2000. http://doi.org/10.1109/36.868878

[10] P. Berardino, G. Fornaro, R. Lanari, and E. Sansosti, "A new algorithm for surface deformation monitoring based on small baseline differential SAR interferograms," IEEE Transactions on Geoscience and Remote Sensing, vol. 40, no. 11, pp. 2375-2383, 2002. http://doi.org/10.1109/TGRS.2002.803792 